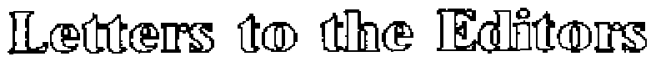

\section{Comments on discrimination of three approaches to evaluate heat fluxes for wall-cooled fixed bed chemical reactors}

(Received 24 July 1992; accepted 8 Jantuary 1993)

Dear Sirs,

In a recent paper, Vortmeyer and Haidegger (1991) presented a comparison of three models to evaluate beat fluxes for wall-cooled fixed-bed chemical reacters. We have the following comments about this paper.

Vortmeyer and Haidegger used the fast exothermic oxidation of ethane to test three (quasi-) homogeneous models. They concluded that the wall heat conduction model was the best becaluse of better agreement with the experimental data and physical reality. We, however, feel that under the tcaction conditions unsidered the homugeneous models are not applicabte, and a heterogeneous model should have been used instead. In a recent article (Wijngagrden and Westerterp, 1989) we explained how improper dependences and relations are introduced when an inproper model is used.

To prove this, we tested Vortmayer and Haidegger's experimental data from their graphs $3(\mathrm{a})-(\mathrm{g})$, with a criterion given by Mears (1971). The interparticle heat transfer resist- ance can be neglected if

$$
\frac{-\left(\Delta H_{p}\right) R\left(T_{p}\right) d_{y}}{2 I_{p} T_{p}}<0.15 \frac{R T_{n}}{E_{a}}
$$

The results of our calculations are presented in Tables 1 and 2. However, the $N u_{\text {p }}$ relations are not given in the paper of Vortmeyer and Haidegger. In the VDI-Wämeatlas (VDL, 1988) $N u_{\text {p }}$ numbers are given for $P e$ above 500 . We refer to the work of Kunii and Sucuki (1967), from which it can be found that $N u_{p}$ for the given $R e$, values varies between 4 and 12. This leads to $47<x_{p}<141 \mathrm{~W} /\left(\mathrm{m}^{2} \mathrm{~K}\right)$. The measured temperatures were assumed to be gas temperatures. In all experiments, particularly just before the hot spot where concentrations and temperatures are relatively high, the criterion is not satisfied. Therefore, temperature differences between catalyst surface and surrounding gas cannot be neglected.

Table 1. Calculation of Mears criterion and catalyst temperature for different experimenta] points and $N u_{p}=4$

\begin{tabular}{|c|c|c|c|c|c|c|}
\hline $\begin{array}{l}\text { Graph } \\
\text { number }\end{array}$ & $\stackrel{T_{8}}{(\mathrm{~K})}$ & $y$ & $\frac{\left(-\Delta H_{r}\right) R\left(T_{q}\right) d_{p}}{2 x_{p} T_{p}}$ & $0.15 \frac{R T_{g}}{E_{a}}$ & $\begin{array}{c}T_{k} \\
\left(\mathrm{~K}^{2}\right)\end{array}$ & $\frac{R\left(T_{\theta}\right)}{R\left(T_{k}\right)}$ \\
\hline $3\{a\}$ & 670 & 0.0033 & 0.069 & 0.009 & 734 & 0.40 \\
\hline 3(b) & 730 & 0.0010 & 0.046 & 0.010 & 753 & 0.81 \\
\hline $3(\mathrm{c})$ & 700 & 0.0017 & 0.057 & 0,009 & 732 & 0.68 \\
\hline 3(d) & 670 & 0,0028 & 0.037 & 0.009 & 690 & 0.69 \\
\hline $3(\mathrm{e})$ & 660 & 0.0033 & 0.056 & 0.009 & 707 & 0.43 \\
\hline $3\left(\mathrm{C}^{\circ}\right)$ & 680 & 0,0030 & 0.075 & 0.009 & 744 & 0.44 \\
\hline $3(g)$ & 700 & 0.0031 & 0.103 & 0.009 & 797 & 0.41 \\
\hline
\end{tabular}

Table 2. Calculation or Mears criterion and catalyst temperature for diferent experimental points and $N_{w_{p}}=12$

\begin{tabular}{|c|c|c|c|c|c|c|}
\hline $\begin{array}{c}\text { Graph } \\
\text { number }\end{array}$ & $\begin{array}{r}T_{v} \\
(\mathbf{K})\end{array}$ & $y$ & $\frac{\left(-\Delta H_{r}\right) R\left(T_{g}\right) d_{p}}{2 \alpha_{p} T_{g}}$ & $0.15 \frac{R T_{a}}{E_{a}}$ & $\begin{array}{l}T_{k} \\
(\mathbf{K})\end{array}$ & $\frac{R\left(T_{\mathrm{Q}}\right)}{R\left(T_{\mathrm{k}}\right)}$ \\
\hline $3(a)$ & 670 & 0.0033 & 0.023 & 0.009 & 680 & 0.82 \\
\hline $3(b)$ & 730 & 0.0010 & 0.015 & 0.010 & 737 & 0.93 \\
\hline $3(c)$ & 700 & 0.0017 & 0019 & 0.009 & 708 & 0.89 \\
\hline 3(d) & 670 & 0.0018 & 0.012 & 0.009 & 675 & 0.90 \\
\hline $3(\mathrm{e})$ & 6601 & 0.0033 & 0.019 & 0.009 & 668 & 0.83 \\
\hline $3(1)$ & 680 & 0.0030 & 0.025 & 0.009 & 691 & 0.83 \\
\hline $3(\mathrm{~g})$ & 700 & $0.003 \mathrm{t}$ & 0.034 & 0.009 & 716 & 0.80 \\
\hline
\end{tabular}



ticle,

Next, the stendy-state heat balance for one catalyst par-

$$
\alpha_{p} A_{p}\left(T_{k}-T_{G}\right)=\frac{V_{p} R\left(T_{k}\right)(-\Delta H,)}{(1-\varepsilon)}
$$

can be solved for $T_{k}$ using the sarne data. It was assumed that all mass transfer resistances are lumped together in the descriplion of the reation rate. Temperature differences between gas and catalyst varying between 5 and $97 \mathrm{~K}$ have been calculated (see Tables 1 and 2). These temperature differences result in a difference in reaction rate varying fromi $7 \%$ to $60 \%$ based on gas and catalyst temperatures. This will certainly lead to erroneous results when using the (quasi-) homogeneous model, particularly in the hot-spot region.

In conclusion, we feel that in important parts of the reactor the temperature diflerences between the particle and the hed are so large that a heterogeneous model should have been used, and that the experimental data collected are not adequate to draw conclusions about the applicability of certain (quasi-) homogeneous models.

\section{K. R. WESTERTERP W. DE JONG G. H. W. VAN BENTHEM}

Department of Chemical Engineering

Twente University of Technology

PO Box 217

7500 AE Enschede

The Nitherlands

\section{NOTATION}

$A_{p} \quad$ external surface area of the catalyst pellet, $\mathrm{m}^{2}$

$d_{p r} \quad$ parlicle diamieler equivalent $\left(=G V_{p} / A_{p}\right)_{r}$ mo
$E_{\text {f }} \quad$ energy of activation, $J / m o l$

( $-\Lambda H_{r}$ ) reaction enthalpy, $\mathrm{J} /$ nol: for exothermic reactions $(-\Delta H)>0$

Nu particle Nusalt nutmber $\left(=x_{p} d_{p} / \lambda_{p}\right)$

$R \quad$ gas constant, $8.314 \mathrm{~J} / \mathrm{mol} \mathrm{K}$

$R(T)$ reaction rate at temperature $T$, mol/m $\mathrm{m}^{3}$ (packedbed volumels

$T_{g} \quad$ temperature of the gas, $\mathrm{K}$

$T_{k} \quad$ temperature of the Gatalyst surface, $\mathrm{K}$

$V_{p}$. volume of the catalyst pellet, $\mathrm{m}^{3}$

$y$. mass fraction of ethane

\section{Greek letters}

$\alpha_{p}$ heat transfer coefficient between the particle and the ges, $W / m^{2} K$

E porosity, volume fraction of the gas in the bed

\section{REFERENCES}

Kunii, D. and Suzuki, $M$, 1967, Particle-to-fiuid heat and mass transfer in packed beds of fine particles. Inf, J. Heat Mass Transfer 10, 845-852.

Mears, D. E., 1971, Tests for transport limitations ì experimental catalytic reactors. Ind. Engng Chem. Process Des. Dev. 10, 541-547.

VDI (Verein Deutscher Ingenieure) 1988, VDI-Gesellschaft Verfahrenstechnik und Chemieingenieurwesen, in VDIWämeatlas, 5. erw. Auflage. VDI-Verlag Düsseldorf.

Vortmeyer, D. and Haidegger, E., 1991, Discrimination of three approaches to evaluate heat fluxes for wall-cooled fixed bed chemical reactors. Chem. Engng Sci. 46, $2651-2660$.

Wijngaarden, R. J. and Westerterp, K. R., 1989, Do the effective heat conductivity and the heal transfer coefficient at the wall inside a packed bed depend on a chemical reaction? Weaknesses and applicability of current models. Chem. Engng Sci. 44, 1653-1663.

\section{Authors' reply to comments by $\mathbf{K} . \mathbf{R}$. Westerterp et $a$.}

(Received 15 October 1992; accopted 8 January 1993)

\section{Dear Sirs,}

Westerterp et al. write that because of too large temperature differences between gas and catalyst partictes, we shullul nul ha ve cluusen the quasi-homogeneous model to interpret our experimental results [1]. Maximum temperature differences of $97 \mathrm{~K}$ are predicted in Table 1 corresponding to the experimental situation shown in Graph $3(\mathrm{~g})$ of our paper [1].

Since in the course of our experimental work we have also felt that, due to chosen inlet and cooling temperatures, this experiment should exhibit the largest temperature difierences between particle and gas, we have measured temperature differences [2] between gas and solid on the centerline of the reactor. Due to technical difficulties we were able to do so only in position 4 of Fig. 1 where, incidentally, the wallcooled reactor had jts hot spot. To measure the particle temperaturc, a specially prepared catalyst particle with a thermocouple in the center was carefully placed on the centerlinc of the reactor at location 4 of Fig. 1. A second thermocouple was placed close to the surface of the particle to obtain the gas tempetature. We took five measurements under steady-state conditions within a few hours and got readings between 4 and $5 \mathrm{~K}$ averaging $\left(T_{k}-T_{n}\right)=4.5 \mathrm{~K}$ instead of $10 \mathrm{~K}$ as evaluated by us according to the equations of Wcsterterpet al. At loction 3 in Fig. 1, which is the point chosen by Westerterp et al., naturally latger differences between the temperatures of catalyst particles and gas have to be expected. Westerterp at al. claim in Table 1 that the difference may be up to $\left(T_{t}-T_{g}\right)=97 \mathrm{~K}$.

We have extended their calculations between thermocouple positions 2 and 4 and have obtained catalyst temperatures $T_{k}$ as plotted in Fig. 1 of this paper. These temperatures are just unimaginable. This view is supported by the experimental work of Wicke et al. [3] who, even under much more severe cunditions than in our work (temperature rise of $300 \mathrm{~K}$ under adjabatic conditions], did not observe such temperature differences for comparable flow conditions. We therefore reject the computed solid temperatures in Table 1 of the letter of Westerterp et al. as unrealistic due to too low particle to fluid heat transfer coeflicients chosen for their calculations.

Let us follow now the theoretical arguments of Westerterp 